\title{
Analysis on the Regional Economic Management From Perspectives of Coordinated Development
}

\author{
Shao-Fang SUN \\ Wuhan Donghu University, Wuhan, Hubei, China \\ 1627466052@qq.com
}

\begin{abstract}
Keywords: coordinated development, regional economic management (REM), evaluation models of qualities

Abstract. The strategy of coordinated development of regional economy (CDRE) is essential to achieve the update of economic structures and a steady and healthy progress of national finance conditions. In the context of the current focused conduction of regional economic plans, it is urgent for China to discuss the patterns behind the coordinated development. This paper aims to improve CDRE and analyze the existing mindset of enhancing regional economic management (REM) patterns. It will build the systematic standards and evaluation models of REM and in the end provide implications on how to improve its mechanism.
\end{abstract}

\section{Introduction}

From the aspect of resource allocation, the nature of REM is to enhance allocating space resources in regions and increase its efficiency under the influence of REM mechanism. Eventually it will lead to the balance of regional economy development and equity in the whole society. However, our REM at present is not on the same level as the regional coordinated development. In this case, the case still remains to be solved on how to improve the existing REM patterns and mechanism, using economic management strategies to fill the gaps of marketing mechanism in the imbalanced regional economic development.

REM is one of the popular study topics in the field of regional economy. Both national and foreign scholars have conducted systematical research on REM patterns with different focuses, such as its definition, nature, goals, mechanism, patterns, quality evaluation and strategy innovations.

Lewis Mumford [1] has come up with the idea of regional coordinated development and he considers both cities and villages equally important. The two areas should be strategically combined together through dividing powers into different sections of city centers to achieve the balance between them. He also emphasizes that the natural environment exerts a more significant impact on economic growth, and therefore the coordinated development must not follow the same pattern of the development based on large cities. Xiushan Chen [2] believes that it is essential to provide equal opportunities of developing economy to each region to solve the imbalance, and the core is to ensure the general efficiency of resource allocation. Meanwhile, Amartya.Sen [3] explains the importance of building the relations between efficiency and equity in regional economic development from economic ethics. Scholars mentioned above share thoughts on solutions of regional imbalance from the key theories of management. Peng Zhou [4] has summarized systematically the REM pattern of the city center area in America and implications behind it, and then has discussed the future direction of REM innovation in 
Yangtze Delta. Ruiqing Song [5] has analyzed our national REM pattern and shared possible plans of building regional management departments. Tingting Pan[6] from another perspective has analyzed the application of "the citistate theory" in Chinese REM, resulting in generating the new pattern of the modern REM. All in all, there is still much to dig in the studies of REM specifically on CDRE patterns. There should be more research on the patterns, mechanism and quality evaluation of REM.

\section{Update of REM Patterns From the Aspect of Coordinated Development}

\subsection{Subject of REM}

China now is following the administrative method of "Level I as subjects, level II as administration". This means that the central government is the first level subject of benefits. The central government and the regional (provincial mostly) governments compose and conduct respective policies of economic management with the same benefit [7]. In terms of REM, the central government is always dominant, since they are the key source of supporting finance for underdeveloped regions. Regional governments have the power make and implement regional policies but the central is still in charge, with unparallel authority when making and coordinating the laws for regional development. Obviously regional governments still are key parts of the REM structure despite their positions. The two sides may not always share the same interest goals under the current tax and assessment system. This empowers regional governments to be both the subject of REM and the representative of regional interest. In fact they are also the primary main object of REM by the central.

\subsection{Aims of REM}

The first aim of REM is to achieve the regional division and coordination of labor as well as the CDRE. First, a reasonable and updated system of regional allocation and coordination of labor is the foundation of health growth of regional and national economy. Outstanding advantages of regions are essential to their regional development and the main evidence for where it may go and how the industrial structure will choose. Second, the gap may be widening between regional economy in the early stage of national economy, and remain the same as the economy grows. When it turns into more developed, the gap will be narrowed and the whole trend is called the theory of "upside-down U" in regional economy ${ }^{[8]}$. From the economic reality now, China should attempt to narrow down the gap based on this theory and enhance the CDRE.

\subsection{Strategies of REM}

The strategies of REM include indirect adjustment and direct control. As our market economy has been constantly updated, our core methods of REM are shaped into the indirect regional finance policies, regional economic policies, regional industrial policies and regional management schemes. Due to the differences in economic and financial development inside our country, a standardized policy of economy and currency can hardly be effective in different regions. Therefore, based on the needs of CDRE, it is necessary to differentiate the policies to each region. This can retain the coordination of regional economy based on those slightly distinguished policies to adjust the regional flows.

However, we are facing a dramatic challenge in regional development, which is the 
expansion of the gap between different regional development and the standardized regional industrial structures. The central and regional government should adopt the regional industrial policies as tools, and put them into practices based on their differences in both regions and developmental stages, according to the location of the regional develop mental resources. Eventually there will be a multiple featured structure of regional industries and a reasonable allocation of labors.

The regional development scheme is about how the central government adjusts the conditions and differences in regions and enhances their progress based on their own features in the economic society. The aim of the scheme is to advance and coordinate all regional economy, maximize the regional efficiency and achieve the optimized allocation of resources.

\section{Evaluation on REM Qualities From Perspectives of Coordinated Development}

\subsection{Evaluation process on REM qualities from perspectives of coordinated}

\section{Development}

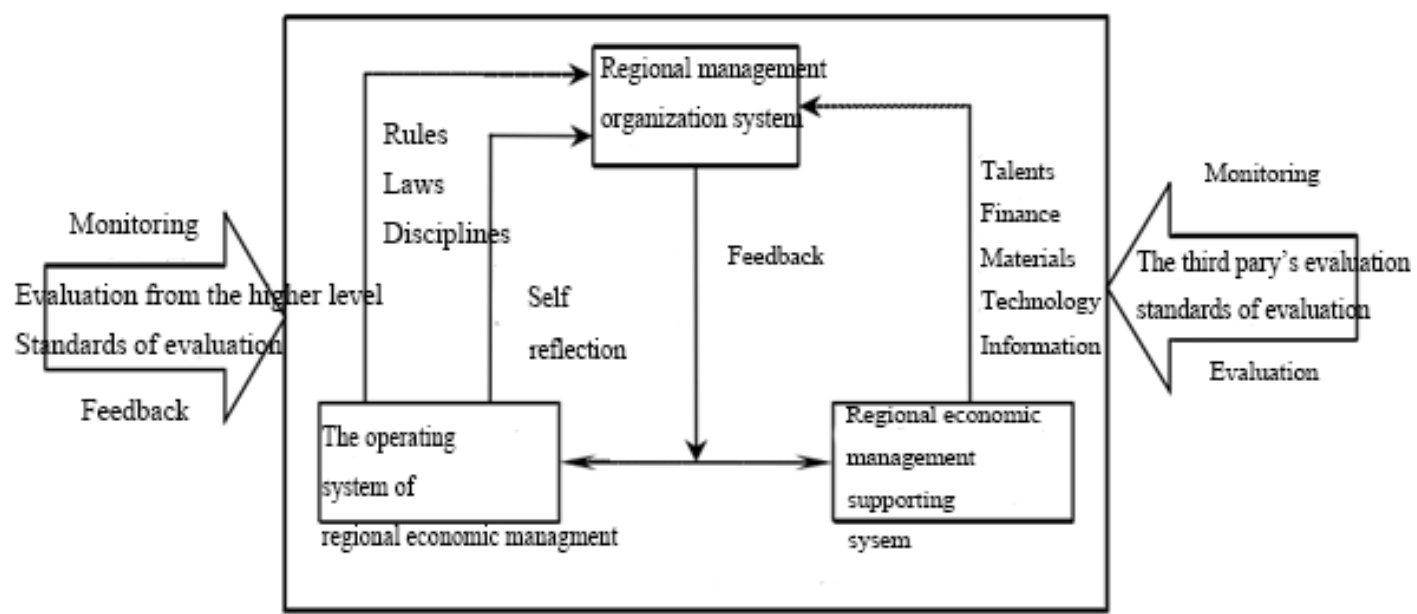

Fig. 1 The Evaluation Process on REM Qualities.

The evaluation on REM qualities is a key step in REM. When enhancing CDRE, there is a lack of evaluation system of REM qualities that is comprehensive, objective and accessible. This disadvantage strains the development and the achievement of REM responsibilities [9]. The evaluation system of REM qualities is a crucial branch of the REM system. The following Figure is its structure and logic. 
3.2 The System of Evaluation Standards of REM qualities from Coordinated Development

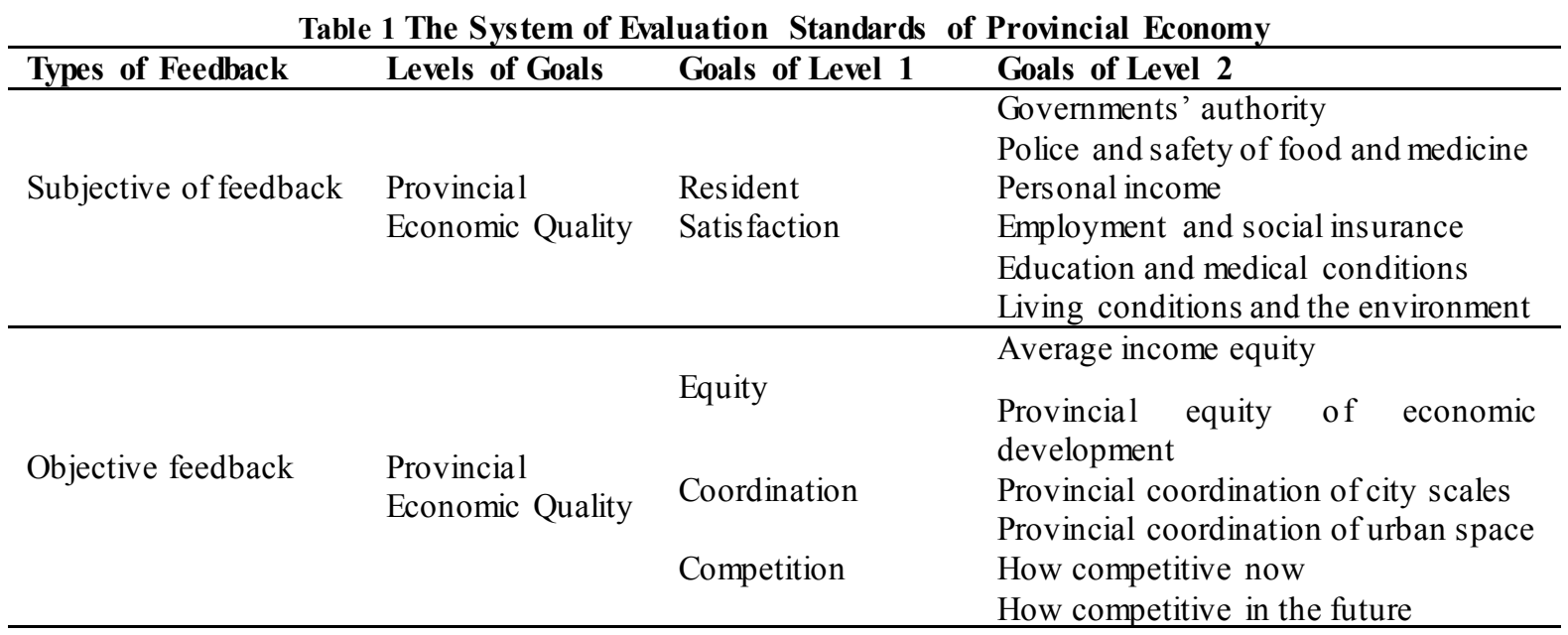

This system is supposed to include the "quantity" evaluation of regional economy, "quality" as well as the future trend. It can certainly fill the gaps of many similar standard systems in some regions and render the data of standard variables accessible. Table 1 is about the system of evaluation standards of provincial economy.

\subsection{Model of the system of evaluation standards of REM qualities from} coordinated development

We assume that $\mathrm{Q}$ represents qualities of REM from coordinated development, $\mathrm{S}$ for resident satisfaction, $\mathrm{T}$ for provincial economic equity, $\mathrm{B}$ for provincial balance and coordination, and $\mathrm{C}$ for provincial economic competition abilities. The model of the evaluation standard, thus, can be $\mathrm{Q}=\mathrm{f}(\mathrm{S}, \mathrm{T}, \mathrm{B}, \mathrm{C})$.

It worth knowing that $\mathrm{S}=\mathrm{k}(\mathrm{G}, \mathrm{F}, \mathrm{I}, \mathrm{W}, \mathrm{D}, \mathrm{H})$. G stands for the authority of government, $\mathrm{F}$ for police and safety of food and medicine, I for individual income, $\mathrm{W}$ for employment and social insurance, $\mathrm{D}$ for education and medical conditions, $\mathrm{H}$ for living conditions and environment.

$\mathrm{T}=\mathrm{g}\left(\mathrm{r}_{1}, \mathrm{r}_{2}\right), \mathrm{r}_{1}$ is equity of average income; $\mathrm{r}_{2}$ is equity of provincial economic development. $\mathrm{B}=\mathrm{h}\left(\mathrm{r}_{3}, \mathrm{r}_{4}\right), \mathrm{r}_{3}$ is the coordination of provincial economy scales; $\mathrm{r}_{4}$ is the special coordination of cities in provincial regions. $C=e\left(r_{5}, r_{6}\right), r_{5}$ is how competitive they are now; $r_{6}$ is how competitive they will be.

\section{Updates of Regional Management Mechanism From Coordinated Development}

\subsection{To update regional management strategies}

To improve regional coordinated development, we should build a management system of strategies combined by the national region scheme, financial policies, economical policies and industrial policies. Governments of all levels should play their leading roles in planning the national development and industrial policy in REM, and use finance and currency policies comprehensively. Currency policies should be further adopted in areas with higher marketing levels, and they will be spread with higher speed and possibly no more problems. For middle-western regions with lower marketing levels, we can mainly 
apply the combination of finance policies and industrial policies which will have a more direct impact to the industry or the company but cannot be implemented without supports of currency, finance and administration methods. In addition, we need to plan out region development based on features of each region, in order to build a basis for the conduction of REM.

\subsection{To build mechanism for sharing regional interest and compensating}

There are comparative advantages and disadvantages in regional cooperation, and the regional interest will inescapably turn from the inferior one to the superior, which may require compensation from the superior to the inferior to achieve the balance of interest. Otherwise, the cooperation is hard to maintain.

Thus, we should start with the adjustment and coordination of regional relations according to the general allocation requirement of the national main function regions. Meanwhile, we are supposed to efficiently lead and arrange key industries gathering in the assigned areas through the compensation system. We should also limit the industrial expansion of some key ecologic functional areas, and ensure that each party is rewarded with interests and compensations during the regional cooperation of main functional areas. This will surely help break the traditions of regional work allocation and then build a more scientific and reasonable one.

\subsection{To build a national department for regional management}

There are existing Chinese departments as the coordinated regional development like "Office of Supporting the Poor", "Office of Western Exploration", "Office of Promoting Northeast", and "Office of Developing the Middle Region". Despite this, their responsibilities are limited and their functions of regional management and coordination are hardly put into practice. It is necessary to set a nation-wide regional management structure based on the unfocused responsibilities in different organizations and departments, and the needs to develop the regional management in regions as a whole. This department will take in charge of planning and conducting relation national regional schemes and policies and monitoring the changing gaps between regions, as well as coordinating the relationship between regions, departments, and levels.

\subsection{To build and perfect the law}

It is an inevitable trend for Chinese regional development practices, to build and perfect the law system of CDRE. In 1980s, there was a popular trend of large-scaled regional cooperation in China, but it cooled down in 1990s. The reason behind it is about the flawed and unsystematic rules, law and disciplines for the regional cooperation events and coordinated development. So far as the requirements of the national coordinated development and interaction, there should be two levels. First is the national level standard and second is the regional support. In this case, for the sake of effective conduction of related policies in underdeveloped regions, the maintenance of authority, stability and constancy, we should speed up building and perfect the law from the two levels [10].

\section{Conclusion}

In order to achieve CDRE, we should not only ensure the basic function works of marketing to regional resource allocation, and encourage the government to control and 
adjust the regional economy, by correcting the imbalanced allocation of regional resources and prevent the over expansion of regional development gaps. Governments should also start from the objects, subjects, goals and approaches of management to enhance the CDRE as the main aim and rebuild the REM patterns. Quality evaluation of REM from coord inated development mainly contains resident satisfaction, provincial economic equity, coordination and competition, whose data model must be built based on these variables to reflect the inner relations between each of them and the quality. Evaluation will be conducted later with solid nature and quality report. Governments should respond with power actions to build the mechanism of effective REM and eventually enhance the CDRE.

\section{References}

[1] Lewis Mumford. Translated by Ling Jun, Wenyan Ni. A City in History (Source, Transformation and Future ) [M]. Beijing: China, China Architecture \& Building Press, 2005(1): pp. 56-66.

[2] Xiushan Chen \& Hong Liu. The Interactive Mechanism Should be Comprehensive in Regional Coordinated Development[J]. Journals for Party and Administrative Cadres, 2006(01): pp. 26-28.

[3] Amartya.Sen. Translated by Yu Wang, Wenyu, Wang. On Ethics and Economics [M]. Beijing: The Commercial Press, 2003: pp. 10-20.

[4] Peng, Zhou. First Analysis on Regional Economic Management Innovation of "Yangtze Delta" [J]. Market Modernization, 2008(12): pp. 265-266.

[5] Ruiqng, Song. Study on Chinese Regional Economic Management Patterns [D]. Lanzhou University, 2012: pp. 30-40.

[6]Tingting, Pan. Appplication of "the citistate theory" in Chinese Regional Economic Management System [D]. Dongbei University of Finance \& Economics, 2011: pp. $36-45$.

[7] Haibing, Gu. Paradigm Study of Chinese Macroscopical Control[J]. Journal of China National School of Administration, 2006(2): pp. 36-39.

[8] Sumei, Luo. Macroscopical Control Views of Regional Economic Development [J]. Statistics \& Decision , 2007(23): pp. 117-118.

[9] Yaping, Zheng. Study on Regional Economic Management Based on Quality Evaluation [D]. China University of Mining and Technology, 2012: pp. 32-42.

[10] Lili, Jiang, Building Frames of Regional Policies Guided by Regional Coordinated Development [J]. World Regional Studies, 2009(6): pp. 56-57. 